\title{
DOENÇAS INTERSTICIAIS PULMONARES
}

\author{
INTERSTITIAL LUNG DISEASES
}

José Antônio Baddini Martinez

Docente da Divisão de Pneumologia do Departamento de Clínica Médica da Faculdade de Medicina de Ribeirão Preto da USP. CoRRESPONDÊNCIA: José A. Baddini Martinez. Departamento de Clínica Médica da Faculdade de Medicina de Ribeirão Preto da Universidade de São Paulo - CEP: 14048-900 - Ribeirão Preto, São Paulo, Brasil - FAX: (016) 633-6695 - email: jabmarti@fmrp.usp.br.

MARTINEZ JAB. $\quad$ Doenças intersticiais pulmonares. Medicina, Ribeirão Preto, 31: 247-256, abr./jun. 1998.

RESUMO: As doenças intersticiais pulmonares são um grupo heterogêneo de patologias, cujas maiores anormalidades ocorrem distalmente aos bronquíolos terminais. Tais doenças costumam ser estudadas conjuntamente, porque compartilham características clínicas, radiológicas, e funcionais comuns. No presente artigo, é discutido o diagnóstico diferencial desse conjunto numeroso de doenças, e, em maior detalhe, algumas das enfermidades mais importantes na prática clínica diária.

UNITERMOS: Doença Pulmonar Intersticial.

\section{INTRODUÇÃO}

A denominação, doença intersticial pulmonar (DIP), é normalmente empregada para designar um grupo numeroso e heterogêneo de patologias, caracterizadas pelo desenvolvimento de infiltrados celulares, e/ou pela deposição de matriz extracelular, nos espaços aéreos distais aos bronquíolos terminais. Como todos esses processos acometem as mesmas regiões dos pulmões, eles adquirem características clínicas, radiológicas e funcionais muito semelhantes, o que não só justifica a sua inclusão num único grupo, como também explica as dificuldades envolvidas com os seus diagnósticos específicos.

Estritamente falando, o termo, interstício pulmonar, refere-se a regiões situadas entre elementos bem definidos do pulmão. Assim, perifericamente, ele corresponde aos espaços existentes entre as células endoteliais e o epitélio alveolar. Ele também inclui os tecidos conectivos perivasculares, peribronquiolares e peribronquiais, desde as paredes dos lóbulos secundários até as regiões mais centrais (Figura 1). A denominação, doença intersticial, surgiu devido ao fato de os primeiros casos de moléstias desse grupo terem sido reconhecidos apenas em fases avançadas de sua evolução, quando mostravam acentuada deposição de tecido fibroso no interstício periférico.Hoje, sabemos que mesmo tais casos de fibrose pulmonar pura apresentaram, em sua fase inicial, um exuberante processo inflamatório, não apenas no interstício, como também na luz alveolar. Devido à grande variedade de estruturas anatômicas que podem estar acometidas nesses processos, um nome mais adequado para o grupo seria "Doenças Infiltrativas Difusas Pulmonares", ou ainda "Doenças Pulmonares Parenquimatosas Difusas". Classicamente, as DIPs englobavam os processos inflamatórios de caráter infiltrativo, com evolução crônica ou subaguda, os quais, se não tratados, evoluiriam para insuficiência respiratória grave, tendo como substrato anatomopatológico uma lesão terminal, o "pulmão em favo de mel". Mais modernamente, o conceito de DIP foi ampliado, também sendo incluídas nesse grupo patologias de instalação aguda, tais como toxicidade por drogas ou vasculites. Outro grupo de doenças, agora estudadas nesse capítulo da Pneumologia, são as patologias bronquiolares do adulto (bronquiolites), as quais freqüentemente acometem, por contigüidade, os espaços alveolares adjacentes. Muito embora diversos processos infecciosos ou neoplásicos pulmonares possam se apresentar, radiologicamente, com infiltrados difusos de aspecto "intersticial", tais moléstias não são estudadas dentro do que se convencionou chamar de DIPs. 


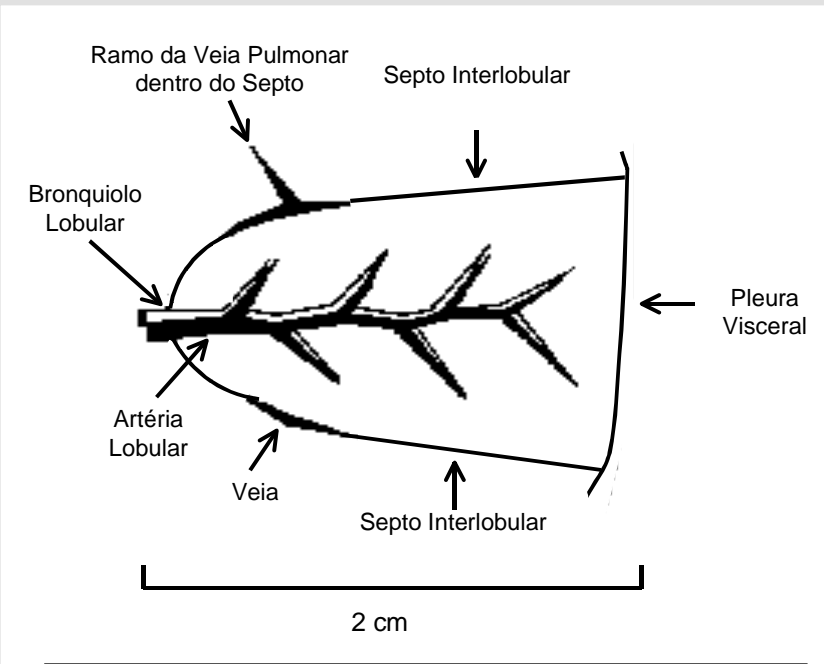

Figura 1 - Anatomia do lóbulo pulmonar e secundário.
Consideradas moléstias pulmonares raras, o número de casos de DIPs vem aumentando nos últimos anos. Em parte, isso se deve ao seu maior reconhecimento por parte da comunidade médica. Outro fator contribuinte seria o surgimento de novos agentes agressores pulmonares, tais como medicamentos, agentes citotóxicos e, mesmo, possíveis fatores ambientais.

\section{CLASSIFICAÇÃO}

Existem mais de cento e oitenta (180) doenças que podem ser englobadas no grupo das DIPs. Tradicionalmente, tais moléstias são classificadas em dois grandes grupos: as de etiologia conhecida e as de etiologia desconhecida (Tabela I). Embora as primeiras sejam as mais numerosas, as últimas são

\section{Tabela I - Classificação das doenças intersticiais pulmonares quanto à etiologia}

\section{- Etiologia Conhecida}

I. Secundárias a Drogas e Tratamentos Medicamentosos

- Agentes antineoplásicos: bleomicina, clorambucil, ciclofosfamida, metotrexate, etc.

- Antibióticos: nitrofurantoina, sulfasalazina, etc.

- Antiinflamatórios: sais de ouro, D-penicilamina, etc.

- Antiarrítmicos: amiodarona, propranolol, procainamida.

- Miscelânea: difenilhidantoína, radiação, oxigênio em altas doses, paraquat, etc.

II. Secundárias a Inalação de Agentes Inorgânicos (Pneumoconioses)

- Silicose, asbestose, beriliose, pneumoconioses por metais pesados, estanhose, etc.

III. Secundárias a Inalação de Agentes Orgânicos (Pneumonites de Hipersensibilidade)

- Doença dos criadores de pássaros, pulmão do fazendeiro, pulmão do umidificador, pulmão dos trabalhadores com queijo, bagaçose, etc.

IV. Secundárias a Outros Agentes

- Inalação de gases tóxicos: cloro, óxidos de nitrogênio, dióxido de enxofre, fósgeno, etc.

- Pneumonias aspirativas crônicas, estenose mitral, pós-infecciosas, etc.

- Etiologia Desconhecida

I. Fibrose Pulmonar Idiopática

II. Sarcoidose

III. Associadas a Colagenoses

- Esclerose sistêmica, dermatopoliomiosite, lúpus eritematosos sistêmico, artrite reumatóide, espondilite anquilosante, doença mista do tecido conectivo, síndrome de Sjögren.

IV. Doenças de Preenchimento Alveolar

- Proteinose alveolar, hemorragia alveolar difusa, pneumonia lipoídica, microlitíase alveolar, pneumonias eosinofílicas, bronquiolite obliterante e pneumonia em organização (BOOP), bronquiolite respiratória, etc.

V. Doenças Císticas Pulmonares

- Granuloma eosinofílico pulmonar, linfangioleiomiomatose, esclerose tuberosa.

\section{Outros Processos}

- Granulomatose de Wegener, vasculites pulmonares, síndrome de Goodpasture, pneumonia intersticial linfocítica, hemossiderose pulmonar idiopática, panbronquiolite difusa, etc. 
mais freqüentes na prática clínica. Devido ao excessivo número de doenças, no presente artigo, abordaremos, inicialmente, os aspectos gerais relacionados com o diagnóstico diferencial dos diferentes processos. A seguir, concentrar-nos-emos em algumas condições que consideramos de maior importância para o clínico.

\section{INVESTIGAÇÃO DIAGNÓSTICA}

\subsection{História clínica e exame físico}

A queixa principal de pacientes com DIP costuma ser dispnéia, freqüentemente presente, há meses ou anos, que piora com a realização de atividades físicas, como andar longas distâncias no plano ou subir escadas. Nos casos muito avançados, ela pode estar presente durante a realização de atividades do cotidiano, como banhar-se ou vestir-se. Tosse seca pode estar presente, mas expectoração abundante ou sibilância não são características das DIPs. Muito importante é a obtenção de um inquérito complementar minucioso, visando detectar sintomas de doenças com manifestações sistêmicas, tais como colagenoses e sarcoidose. A investigação do uso de medicamentos e drogas potencialmente tóxicas, tanto no presente como no passado, e de exposições ambientais profissionais ou domésticas, é de fundamental importância para a detecção de quadros de toxicidade pulmonar, pneumoconioses, pneumonites de hipersensibilidade, e outros. Nesse contexto, não deve ser esquecido o questionamento sobre atividades de lazer e a criação de animais, em especial aves. Ao exame físico, o achado de baqueteamento digital, embora não específico, é altamente sugestivo de fibrose pulmonar idiopática (FPI). À ausculta, a presença de estertores finos profusos (em velcro ou em manguito) sugere doença fibrótica avançada.

\subsection{Radiografia simples de tórax}

Embora permita o diagnóstico sindrômico da doença, é de pouca utilidade no diagnóstico diferencial entre os diferentes processos. O reconhecimento do padrão radiológico predominante (macro ou micronodular, alveolar, reticular ou cístico), e a distribuição dessas lesões pode sugerir patologias específicas. Assim, infiltrados reticulares difusos, predominando em bases e cursando com volumes pulmonares reduzidos, costumam corresponder a FPI, ou comprometimento pulmonar por algumas colagenoses. Já infiltrados micronodulares, acometendo ápices ou campos médios, com volumes preservados e adenomegalia hilar, suge- rem sarcoidose. Doenças císticas, como granuloma eosinofílico (GE) e linfangioleiomiomatose (LAM), habitualmente, cursam com hiperinsuflação pulmonar e uma maior incidência de pneumotórax.

\subsection{Tomografia computadorizada de tórax de alta resolução (TCAR)}

É um exame mais sensível e específico do que a radiologia torácica convencional, capaz de detectar doença mesmo na presença de radiografias normais. As imagens que a TCAR fornece podem ser comparadas à visão que um observador atento teria, ao vasculhar, com o auxílio de uma lupa de pequeno aumento, cortes transversais obtidos em diferentes níveis pulmonares. Assim, estruturas como o lobo pulmonar secundário ficam mais evidentes, e padrões peculiares de distribuição podem ser caracterizados (Figura 1). Algumas DIPs tendem a apresentar uma distribuição de lesões centradas nos bronquíolos, como é o caso das bronquiolites e do GE. Outros processos tendem a mostrar uma preferência pelo acometimento linfático, como ocorre tipicamente com as linfangites carcinomatosas e patologias granulomatosas. Processos que tendem a evoluir para fibrose intersticial e insuficiência respiratória progressiva, tal como a FPI, mostram padrões predominantemente reticulares, com espessamento dos septos interlobares, e localização predominantemente subpleural. Pela combinação dos padrões de distribuição acima, tem-se chegado a quadros tomográficos bastante específicos para algumas DIPs, o que poderá reduzir as indicações de biópsias pulmonares. Pacientes com LAM, por exemplo, mostram inúmeros cistos de pequeno volume e aspecto homogêneo, distribuídos uniformemente em ambos os pulmões. Casos de GE costumam mostrar imagens císticas semelhantes, mas de distribuição broncocêntrica e, preferencialmente, acometendo os ápices pulmonares. Uma outra característica importante da TCAR é a sua capacidade de fornecer informações sobre o grau de inflamação e fibrose, existentes em um determinado caso. Admite-se, atualmente, que a presença do padrão radiológico, conhecido como vidro despolido ( ground glass), guarde relação com lesões mais celulares, exsudativas e inflamatórias, e, portanto, seja um marcador de doença inicial, com potencial para uma boa resposta terapêutica.

\subsection{Testes de função pulmonar}

Tais exames, habitualmente, não contribuem de maneira significativa para o diagnóstico diferencial 
entre os processos, mas são necessários para a avaliação da gravidade da doença, bem como, ao serem repetidos periodicamente, na avaliação do grau de resposta ao tratamento. A espirometria, associada a medidas do volume residual e da capacidade de difusão do monóxido de carbono (DLCO), são os testes indicados. Tipicamente são evidenciados quadros de restrição pulmonar, muito embora defeitos ventilatórios obstrutivos, às vezes, sejam notados, como, por exemplo, em alguns casos de sarcoidose e na LAM. Os pacientes com DIPs, geralmente, apresentam hipoxemia arterial, por vezes, de grau grave, que se acentua com a atividade física. Na sua gênese, estão distúrbios da relação ventilação/perfusão e perturbações difusionais, as quais costumam manifestar-se durante o exercício. Os defeitos das trocas gasosas são melhor estudados por meio de testes controlados, de exercícios realizados em cicloergômetro ou esteira. Tais estudos, juntamente com o DLCO, são considerados os métodos funcionais mais sensíveis para a detecção precoce de DIPs.

\subsection{Lavado broncoalveolar (LBA)}

A técnica da lavagem broncoalveolar, através de fibrobroncoscópio encravado em um segmento brônquico periférico, há anos vem sendo utilizada no estudo das DIPs. O procedimento, normalmente, é feito pela injeção com seringas, através do canal do broncoscópio, de repetidas alíquotas de soro fisiológico, até ser atingido um volume final próximo a $200 \mathrm{ml}$. Esse soro é prontamente aspirado, sendo o material recuperado rico em elementos celulares e mediadores inflamatórios, provenientes das porções mais distais dos pulmões. Esse material é, então, submetido a estudos citológicos e avaliações bioquímicas diversas, tais como dosagens de citoquinas. Em certas situações, esse procedimento pode ser diagnóstico, poupando o paciente de uma biópsia pulmonar. Isso pode ocorrer, por exemplo, nos casos de hemorragia alveolar, no achado de material lipoproteináceo, em casos suspeitos de proteinose alveolar, na pesquisa de inclusões citoplasmáticas por microscopia eletrônica no GE, ou na identificação de gotículas de gordura no citoplasma de macrófagos, em pacientes com aspiração crônica. O LBA também apresenta enorme importância na pesquisa de infecções, em especial por germes oportunistas. Em se tratando de DIPs, contudo, na maioria das vezes, a informação obtida é apenas acessória, em meio aos outros dados de investigação diagnóstica. $\mathrm{O}$ uso do lavado tem definido relações entre alguns quadros pulmonares e certos perfis de celularidade. Aumento de celularidade às custas de neutrófilos e, eventualmente, de eosinófilos, costuma ser visto em casos de FPI e quadros associados a colagenoses. Aumento da celularidade, às custas de linfócitos, pode ser observado na sarcoidose e pneumonites de hipersensibilidade (PH). Embora essas duas condições possam cursar com grandes elevações dos linfócitos, habitualmente, a relação $\mathrm{CD} 4 / \mathrm{CD} 8$ é elevada na primeira e reduzida na última. Admite-se que a linfocitose no LBA de pacientes com sarcoidose guarde relação com a atividade inflamatória da doença. Também se tem demonstrado que as elevações das contagens linfocitárias, em pacientes com FPI, se associam a maiores chances de resposta clínica ao tratamento com corticosteróides. Embora seja um método valioso na pesquisa dos mecanismos celulares e inflamatórios, envolvidos com a patogênese das doenças intersticiais, o uso rotineiro do LBA, na condução clínica desses processos, ainda não é consenso entre os diferentes autores.

\subsection{Biópsias transbrônquicas}

O exame histopatológico do tecido pulmonar é o método definitivo para o diagnóstico das DIPs. Biópsias transbrônquicas são obtidas por meio de pinças apropriadas, durante a realização de fibrobroncoscopias com os pacientes levemente sedados. Tais pinças são direcionadas para a periferia do pulmão até ser encontrada resistência. Nesse momento, sua extremidade cortante "em jacaré" é aberta, e biopsia um pedaço da parede de um brônquio de pequeno calibre, trazendo consigo o tecido alveolar adjascente. Apesar da sua praticidade, os fragmentos de tecido obtidos com esse tipo de biópsia são pequenos, causando dificuldades de interpretação para os patologistas. Idealmente, devem ser obtidas sete biópsias transbrônquicas de bom tamanho, para que as chances de diagnóstico sejam maiores. As biópsias transbrônquicas se revelam particularmente úteis em patologias de distribuição peribrônquica ou linfática, e com características histológicas bem definidas, como é o caso da sarcoidose, silicose e proteinose alveolar. Esse tipo de biópsia também permite diagnosticar ou excluir a presença de linfangite carcinomatosa e certos quadros infecciosos, como tuberculose ou pneumocistose. Freqüentemente, contudo, os achados histológicos são inespecíficos, devido às pequenas dimensões dos fragmentos obtidos.

\subsection{Biópsia pulmonar cirúrgica}

Estará sempre indicada, quando os achados da biópsia transbrônquica forem inconclusivos, e o pa- 
ciente reunir condições clínicas adequadas para a cirurgia. Ultimamente, a abordagem por minitoracotomia vem sendo substituída pela videotoracoscopia, a qual tem reduzido em muito a morbidade do procedimento. É recomendável a obtenção de dois ou três fragmentos de pulmão, preferencialmente do lobo superior e inferior do hemitórax abordado. O cirurgião poderá orientar a biópsia pelos achados tomográficos, de tal modo que áreas com doença em fase inicial, intermediária, e avançada sejam igualmente representadas nas amostras. A obtenção de um volume expressivo de tecido, habitualmente, permite ao patologista definir claramente o padrão histológico, bem como, particularmente, nas doenças fibróticas, dar informações sobre o estadiamento do processo, em função da quantidade relativa de inflamação e fibrose presentes. Portanto, tal procedimento, além de fornecer um diagnóstico específico, nas doenças que evoluem para fibrose, traz informações de natureza prognóstica, e das chances de resposta ao tratamento. A patologia das DIPs é assunto complexo, o que é agravado pela raridade dessas condições. Em função disso, tais biópsias devem ser vistas por patologistas com experiência na área, preferencialmente, por um bom patologista pulmonar.

\section{ENTIDADES ESPECÍFICAS}

\subsection{Fibrose Pulmonar Idiopática}

Ao contrário do que o seu nome possa sugerir, FPI é uma doença bem definida, com características clínicas, radiológicas, funcionais e histopatológicas próprias. O termo "idiopática" indica apenas que a sua etiologia é desconhecida. Curiosamente, dados recentes mostram uma maior incidência da doença em indivíduos fumantes, expostos a queima de lenha, ou relatando passado de trabalho com madeira. Na sua gênese, já foram levantados fatores genéticos, infecções virais, e processos inflamatórios autoimunes. De fato, é bem reconhecida uma forma familiar da moléstia, mas os estudos genéticos, realizados nessa condição, ainda não são conclusivos. A teoria mais aceita para o desenvolvimento da FPI supõe que a ocorrência de insultos ambientais em indivíduos susceptíveis, tais como hipotéticas infecções virais, ajam como agentes desencadeantes de uma cascata inflamatória ao nível pulmonar. Tais agentes agressores, ao lesarem tecidos e células pulmonares, desencadeariam uma resposta inflamatória aguda que caracterizaria a fase inicial da doença, freqüentemente chamada de alveolite. Essa resposta, em condições fisiológicas, seria autolimitada, mas, nos casos de FPI, perpetuar-se-ia num estado de cronicidade, devido a razões desconhecidas, promovendo graves transtornos dos mecanismos de reparação pulmonar. Histologicamente, tais distúrbios, habitualmente, se traduzem por um aspecto de doença não uniforme, com áreas de pulmão normal coexistindo adjacentes a áreas de inflamação, representadas por infiltrados linfocitários septais, e a áreas de proliferação fibroblástica e deposição colágena. A medida em que o processo avança, a intensa deposição de colágeno e o colápso dos septos alveolares levam à formação de grandes espaços aéreos císticos, delimitados por paredes fibrosas espessas e revestidos por epitélio metaplásico bronquiolar. Esse último aspecto é chamado pulmão em favo de mel (honeycombing lung) e representa a via final do processo. O padrão anatomopatológico descrito acima corresponde à chamada "pneumonia intersticial usual" (em inglês UIP), substrato histológico mais freqüentemente associado a FPI, o qual também pode ser encontrado em outras DIPs como, por exemplo, em casos de artrite reumatóide ou esclerose sistêmica. Um segundo padrão histológico, que também pode estar presente na FPI, é a chamada "pneumonia intersticial descamativa" (em inglês $D I P)$.

Clinicamente, a FPI acomete pessoas de meia-idade, geralmente entre quarenta (40) e setenta (70) anos, com uma discreta predileção por homens. A doença tem início insidioso e a queixa principal é geralmente dispnéia. Embora alguns indivíduos queixem-se, primeiramente, de tosse seca, todos os pacientes apresentarão dispnéia em exercício, à medida em que a doença evolua. Ao exame físico, estertores finos são o achado mais comum, e baqueteamento digital pode ocorrer em até $70 \%$ dos casos. A radiografia de tórax costuma mostrar volume pulmonar reduzido, com um infiltrado bilateral reticular ou reticulonodular. Tal infiltrado, normalmente, é difuso, com predomínio nas bases pulmonares. Infiltrados reticulados grosseiros, com imagens areolares múltiplas, costumam ser vistas em fases muito avançadas da doença. A TCAR de tórax permite um estudo muito mais sensível e detalhado dessas lesões (Figura 2). Através dela fica claro que os infiltrados na FPI concentram-se, preferencialmente, nas regiões subpleurais. O envolvimento é desigual, com áreas de reticulação alternando-se com áreas de tecido normal e honeycombing. Outros achados encontrados são: 1) espessamento discreto e 


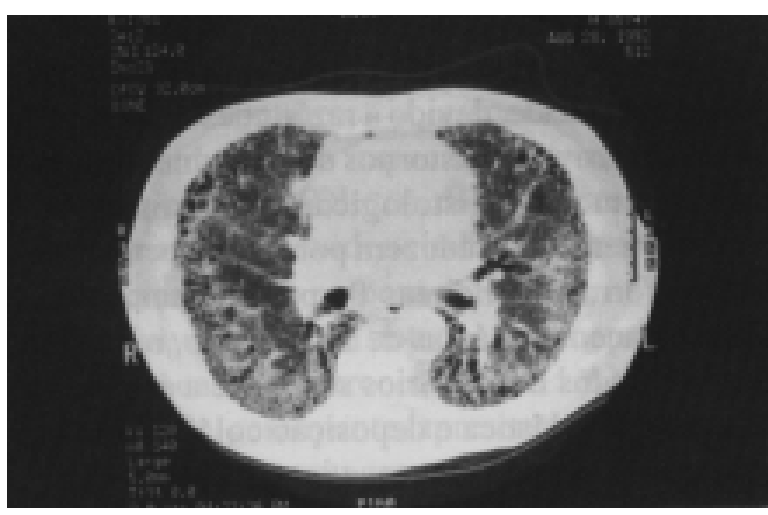

A

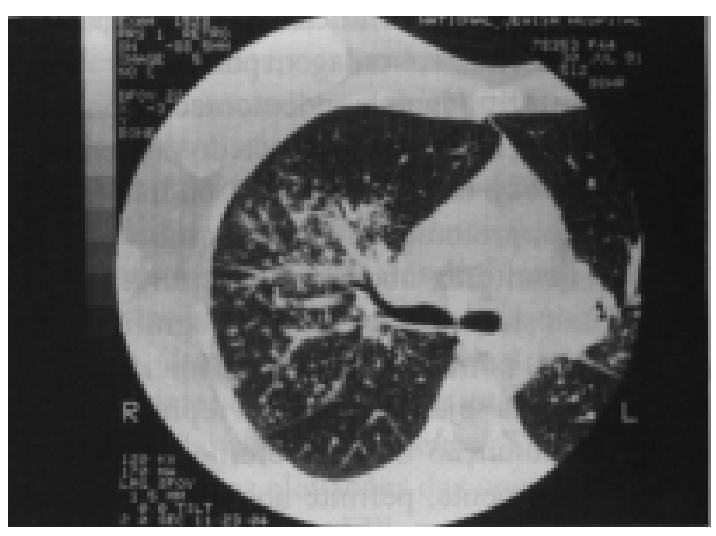

B

Figura 2 - A: TCAR de paciente portador de FPI. B: TCAR de paciente portador de sarcoidose. Veja texto para detalhes.

irregularidades finas ao nível da interface pleura visceral - pulmões; 2) aspecto de irregularidade fina na superfície dos vasos; 3 ) espessamento e irregularidade do desenho das paredes brônquicas; 4) presença de bronquiectasias de tração; 5) freqüência variável de áreas em vidro despolido, em meio às diversas alterações.

Pacientes com FPI, geralmente, apresentam padrões espirométricos restritivos, com volumes e capacidades pulmonares reduzidas. A ocorrência de fluxos expiratórios supranormais se correlaciona com doença fibrótica avançada e é um indicador de mal prognóstico. Quando existe história de tabagismo intenso associado, as alterações funcionais podem ser menos típicas. Nessas situações, devido a lesões enfisematosas superajuntadas, os volumes pulmonares tendem a ser preservados, o DLCO atinge valores muito baixos, e a hipoxemia arterial é mais grave. Vale ainda salientar que pacientes com FPI podem mostrar títulos elevados de fator reumatóide e autoanticorpos não específicos, sem isso significar presença de doença do colágeno.

O tratamento da FPI baseia-se, inicialmente, na administração de prednisona, na dose de $1,0 \mathrm{mg} / \mathrm{kg} / \mathrm{dia}$. Nessas doses, são comuns efeitos colaterais importantes, tais como intolerância à glicose, edemas, ganho de peso, epigastralgia e hipertensão arterial. O médico que assiste ao doente deverá, portanto, estar atento para a detecção e controle dessas complicações. Procura-se manter as altas doses de esteróides por períodos de oito (8) a doze (12) semanas, momento no qual uma reavaliação funcional é feita. Caso haja melhora ou estabilização clínico-funcional, o esteróide é redu- zido lenta e progressivamente, até que se complete, pelo menos, um ano de tratamento. Na eventualidade de uma deterioração em vigência de esteróides, costuma-se associar ciclofosfamida oral, nas doses de $2 \mathrm{mg} / \mathrm{kg} / \mathrm{dia}$, ao mesmo tempo em que se reduz a prednisona para doses em torno de $0,25 \mathrm{mg} / \mathrm{kg} / \mathrm{dia}$. Embora costume ser melhor tolerada que os esteróides, a ciclofosfamida é uma droga potencialmente mais tóxica, podendo causar leucopenia, cistite hemorrágica, alopécia, plaquetopenia, anemia, esterilidade e, a longo prazo, câncer.

Embora o curso clínico dos casos de FPI possa ser variado, na maioria das vezes, a evolução não costuma ser boa. A mortalidade, quatro anos após o diagnóstico, gira em torno de 50\%, e apenas 30\% dos pacientes vão mostrar algum grau de resposta ao tratamento. Admite-se que as chances de sucesso terapêutico são maiores nos casos diagnosticados numa fase inicial, na qual as alterações inflamatórias preponderem sobre as lesões fibróticas irreversíveis. Isso enfatisa a necessidade do reconhecimento e tratamento precoce dessa condição. Em casos selecionados de pacientes com insuficiência respiratória grave, o transplante pulmonar se apresenta hoje como uma opção terapêutica viável.

\subsection{Sarcoidose}

A sarcoidose é uma doença multissistêmica, de etiologia desconhecida, caracterizada, histologicamente, pelo achado de granulomas epitelióides não caseosos, os quais, muito freqüentemente, acometem os pulmões e/ou linfonodos torácicos. Os pulmões, geralmente, estão envolvidos microscopicamente, mes- 
mo quando as radiografias de tórax são normais. $\mathrm{O}$ aspecto anatomopatológico mostra granulomas não necrotizantes, com tendência a se coalescerem, distribuindo-se ao longo das vias linfáticas na pleura, septos interlobulares, e ao longo dos feixes broncovasculares. Uma quantidade pequena de degeneração ou necrose fibrinóide comumente é encontrada em granulomas sarcoidóticos típicos. Na maioria das vezes, também está presente um infiltrado intersticial mononuclear discreto.

A sarcoidose costuma acometer pessoas entre a segunda e quarta décadas de vida, sem predileção por sexo, mas com formas de apresentação mais floridas e agressivas em indivíduos da raça negra. As queixas respiratórias podem ser muito pobres, não raro a doença sendo diagnosticada devido a um achado radiológico. Nas formas mais avançadas de comprometimento pulmonar, a queixa mais comum é dispnéia relacionada ao exercício. O exame do tórax costuma ser pobre, sendo encontrados estertores finos nos casos de evolução para fibrose. Sibilos e broncoespasmo podem surgir, quando houver estreitamento brônquico, secundário ao crescimento de granulomas ao nível submucoso. Segundo James ${ }^{(1)}$, dor do tipo pleural, der- rame pleural, e baqueteamento digital são achados tão infreqüentes, que a presença de um deles significa alta probabilidade de outro diagnóstico. Todo paciente com suspeita de sarcoidose deve ser minuciosamente examinado, devido à possibilidade de manifestações extratorácicas da doença (Tabela II).

Radiologicamente, a sarcoidose pode ter apresentação variada. Em suas fases iniciais, costuma mostrar infiltrados simétricos de predomínio nodular ou micronodular, às vezes associados a um aspecto de opacificação tênue, em vidro despolido. Tais infiltrados têm uma tendência a acometer mais os campos médios e os terços superiores dos pulmões. Adenomegalias hilares e mediastinais são achados freqüentes. Em fases mais avançadas, infiltrados reticulares predominam, e imagens em favo de mel também podem ser distinguidas. Nesses casos, o comprometimento pulmonar pode ser difuso, associado a volumes pulmonares pequenos, lembrando FPI. Vale salientar que alguns casos crônicos de sarcoidose podem mostrar predomínio apical, nódulos confluentes e imagens cavitárias, simulando, assim, tuberculose pulmonar. É habitual estagiar a sarcoidose torácica em função dos seus achados radiológicos, como descrito

Tabela II - Manifestações Sistêmicas da Sarcoidose

\begin{tabular}{|c|c|c|}
\hline Comprometimento & Manifestações & $\begin{array}{c}\text { Incidência } \\
\text { (Segundo James) }^{(1)}\end{array}$ \\
\hline Pulmão e Linfonodos Torácicos & $\begin{array}{l}\text { Infiltrados reticulonodulares com ou sem } \\
\text { adenopatias associadas. }\end{array}$ & $87-96 \%$ \\
\hline Olhos & $\begin{array}{l}\text { Uveíte anterior e posterior, iridociclite, conjunti- } \\
\text { vite flictenular, obstrução do ducto lacrimal, etc. }\end{array}$ & $15-27 \%$ \\
\hline Pele & $\begin{array}{l}\text { Eritema nodoso, lúpus pérnio, placas, erupções } \\
\text { maculopapulares, cicatrizes e quelóides. }\end{array}$ & $26-52 \%$ \\
\hline Sistema Nervoso & $\begin{array}{l}\text { Paralisia facial, paralisia de nervos cranianos, } \\
\text { neuropatia periférica, miopatia, meningite, le- } \\
\text { sões expansivas cerebrais. }\end{array}$ & $4-9 \%$ \\
\hline Coração & $\begin{array}{l}\text { Miocardiopatia, distúrbios de condução, ICC, } \\
\text { arritmias e morte súbita. }\end{array}$ & $5-27 \%$ \\
\hline Ossos e Articulações & $\begin{array}{l}\text { Cistos ósseos, edema de partes moles, rigidez } \\
\text { articular, artralgias e artrite. }\end{array}$ & $4-34 \%$ \\
\hline Glândulas Salivares & Aumento das paróticas. & $4-6 \%$ \\
\hline Fígado e Baço & Hepatoesplenomegalia. & $12-20 \%$ \\
\hline Hipercalcemia e Hipercalciúria & Nefrocalcinose. & $11-18 \%$ \\
\hline
\end{tabular}


na Tabela III. Tal classificação pressupõe que exista uma progressão contínua entre os diferentes estágios, o que nem sempre ocorre. A TCAR permite evidenciar mais facilmente as adenopatias mediastinais. Além disso, ela costuma mostrar um padrão muito típico, com lesões nodulares múltiplas, distribuindo-se em áreas de projeção linfática, tais como regiões subpleurais e peribroncovasculares (Figura 2). Esse último tipo de distribuição explica porque biópsias transbrônquicas são um método bastante efetivo no diagnótico dessa condição.

\begin{tabular}{|c|c|}
\hline Estádio & Alterações \\
\hline 0 & Radiografia sem alterações. \\
\hline 1 & Linfadenopatia hilar isolada. \\
\hline II & $\begin{array}{l}\text { Linfadenopatia hilar e infiltrados } \\
\text { pulmonares. }\end{array}$ \\
\hline III & $\begin{array}{l}\text { Infiltrados pulmonares sem adeno- } \\
\text { megalias associadas. }\end{array}$ \\
\hline $\mathrm{IV}^{*}$ & $\begin{array}{l}\text { Lesões fibróticas avançadas sem } \\
\text { adenomegalias. }\end{array}$ \\
\hline
\end{tabular}

* Um número significante de autores incluem essa categoria dentro do estádio III.

Pacientes com sarcoidose tipicamente apresentam depressão da imunidade celular e uma hiperreatividade da imunidade humoral. Tais fenômenos são traduzidos, laboratorialmente, por uma anergia a antígenos cutâneos tais como o PPD, hipergamaglobulinemia, e um nível elevado de imunocomplexos circulantes. A injeção intradérmica de extrato obtido de baço ou linfonodos de paciente sarcoidótico provoca o surgimento de lesões granulomatosas típicas na pele de um outro portador da moléstia, quatro semanas após a administração. Tal teste é chamado reação de Kveim e é preconizado como método diagnóstico auxiliar da doença. A falta de antígenos adequadamente padronizados e comercializados, entretanto, impede o seu uso rotineiro. $\mathrm{Pa}$ cientes com sarcoidose podem mostrar aumento dos níveis séricos da enzima conversora da angiotensina, muito embora outras patologias granulomatosas também possam cursar com tais elevações. Hipercalcemia e hipercalciúria são achados freqüentes, devido à absorção intestinal excessiva, secundária à hiperprodução de 1,25 dihidroxi - vitamina $\mathrm{D}$, pelas células dos granulomas epitelióides.

O curso e prognóstico da sarcoidose correlacionam-se com seu modo de apresentação. Um início agudo, caracterizado por febre alta e eritema nodoso, costuma ter evolução autolimitada com regressão espontânea. Uma doença de instalação insidiosa tem maiores chances de evoluir para fibrose pulmonar irreversível e insuficiência respiratória grave. A presença de comprometimento extratorácico, incluindo hipercalcemia ou hipercalciúria, é indicação indiscutível para tratamento. Quadros de artrite ou eritema nodoso podem ser controlados apenas com antiinflamatórios não hormonais. Em todas as demais situações, a terapêutica de escolha são os corticosteróides em altas doses. A maioria dos autores, atualmente, concorda que doentes em estádio I, sem sintomas ou manifestações extratorácicas, devam apenas ser seguidos clinicamente com radiografias semestrais. Pacientes em estádio II, com sintomas ou alterações em provas de função pulmonar, devem ser tratados. Pacientes em estádio II, assintomáticos e sem alteração funcional, poderão ser observados de perto e reavaliados após um período de três a seis meses, devido à possibilidade de regressão espontânea. Muitas autoridades, porém, preconizam o tratamento medicamentoso imediato, em tais casos. Pacientes em estádio III e IV sempre deverão ser tratados. O esteróide utilizado normalmente é a prednisona, em doses orais iniciais variando entre 40 e $60 \mathrm{mg}$ ao dia. Essas doses deverão ser mantidas por um período de quatro (4) a oito (8) semanas e, progressivamente, decrescidas em função da resposta clínica. O tempo total de tratamento é variável, podendo ir de seis (6) a doze (12) meses. Nos casos em que os esteróides falham, ou não possam ser usados, são opções terapêuticas alternativas o metotrexate, azatioprina, ciclofosfamida, clorambucil e cloroquina.

\subsection{Pneumonites de Hipersensibilidade}

O termo pneumonite de hipersensibilidade designa um grupo de doenças resultantes da inalação repetida e da sensibilização a um grande número de partículas orgânicas. Menos freqüentemente, essa sensibilização se dá a inalantes químicos de baixo peso molecular. Também conhecida como alveolite alérgica extrínseca, a importância dessa moléstia reside no fato de, uma vez identificado e afastado o agente causador, ela poder estabilizar-se ou reverter totalmente. A lista de agentes que podem causar 
PH é extensa, e uma pequena amostra delas está contida na Tabela IV. O diagnóstico de PH depende, principalmente, de um apurado senso clínico. Uma história bem feita, que sugira uma relação temporal entre os sintomas e certas atividades profissionais ou passatempos, freqüentemente é a melhor pista para se chegar ao diagnóstico. A história ambiental deve-se estender ao ambiente doméstico, indagando-se sobre a presença de umidade, vazamentos, bolor, e criação de animais. Classicamente, a PH é dividida em aguda e crônica. Na primeira, sintomas, tais como febre, fraqueza, dores musculares, tosse, dispnéia e aperto no peito, aparecem quatro a doze horas após a exposição ao agente, como, por exemplo, feno mofado. Ao exame físico, febre e estertores finos podem ser evidenciados. A forma aguda costuma ser autolimitada, os sintomas desaparecendo vinte e quatro (24) horas após o seu início, até o momento em que uma nova exposição ocorra. A forma crônica, normalmente, se associa às maiores dificuldades diagnósticas. Dispnéia ao exercício e tosse seca são os sintomas predominantes. Cansaço e perda de peso também podem estar presentes. $\mathrm{O}$ exame físico pode ser normal ou evidenciar estertores difusos. Sibilos têm sido descritos em alguns pacientes, e um tipo particular de som respiratório, denominado grasnido, é particularmente sugestivo de PH. O pulmão dos criadores de pássaros, em particular, costuma ter evolução silenciosa, não raro sendo diagnosticado apenas em fases avançadas de insuficiência respiratória.

A radiografia de tórax, nas formas agudas de $\mathrm{PH}$, pode ser normal, mas, tipicamente, mostra nódulos micronodulares, disseminados ou de predomínio basal. Infiltrados, em vidro despolido, difusos, também podem estar presentes. Nas formas crônicas, infiltrados reticulares, disseminados acometem ambos os pulmões. Os volumes pulmonares podem estar mantidos ou diminuídos, e existe uma tendência para o acometimento ser maior em lobos superiores. A TCAR, nessa fase, costuma mostrar áreas de densidades lineares e faveolamento, simulando FPI. Contudo, a associação de nódulos centrilobulares, em profusão variável, e áreas de vidro despolido com distribuição desigual, falam a favor de PH crônica.

O diagnóstico de $\mathrm{PH}$, geralmente, é confirmado por biópsia cirúrgica. Histologicamente, os achados são de uma bronquiolite celular, associada a um infiltrado intersticial mononuclear e a alguns granulomas. Tais granulomas costumam ser pequenos e freqüentemente malformados, mostrando-se mais como um acúmulo frouxo de células epitelióides. Alguns casos podem mostrar áreas de bronquiolite obliterante e pneumonia em organização (em inglês $B O O P$ ) associadas. Em casos crônicos, um padrão tipo UIP, indistinguível da FPI, já foi descrito.

$\mathrm{O}$ tratamento da $\mathrm{PH}$ baseia-se, primordialmente, na detecção e afastamento do antígeno causador do processo, objetivo que nem sempre é facilmente atingido. A terapia medicamentosa baseia-se no uso de prednisona, inicialmente, em altas doses, com redução progressiva do medicamento em função da resposta obtida. O curso clínico dos casos de PH é variável, mas o prognóstico costuma ser bom, desde que a doença seja detectada em fase não muito avançada.

Tabela IV - Algumas causas selecionadas de pneumonite de hipersensibilidade

\begin{tabular}{lll}
\hline \multicolumn{1}{c}{ Antígeno } & \multicolumn{1}{c}{ Exposição } & \multicolumn{1}{c}{ Doença } \\
\hline $\begin{array}{l}\text { Micropolyspora faeni } \\
\text { Aspergillus sp., etc. }\end{array}$ & Feno mofado & Pulmão do fazendeiro \\
Thermoactinomyces sacchari & Cana de açúcar mofada & \\
Thermoactinomyces candidus & Reservatórios de água aquecidos. & Bagaçose \\
Naegleria gruberi, etc. & Água contaminada & Pulmão do umidificador ar condicionado \\
Proteínas aviárias & Penas e excretas aviárias & Pulmão do criador de pássaros \\
Proteínas animais & Urina, soro e pelos de roedores, & Pulmão dos tratadores de animais \\
& coelhos, e outros mamíferos & Pulmão do peleteiro \\
Sulfato de cobre & Mistura de Bordeaux & Pulmão dos plantadores de uva \\
Sulfato diazobenzeno de sódio & Reagente de cromatografia & Alveolite do reagente de Pauli \\
\hline
\end{tabular}


MARTINEZ JAB. Interstitial lung diseases. Medicina, Ribeirão Preto, 31: 247-256, apr./june 1998.

ABSTRACT: The interstitial lung diseases are a non homogeneous group of disorders, which anatomical abnormalities occur within the regions of the lung distal to the terminal bronchioles. These diseases are generally studied all together, because they share common clinical, radiological, and physiological features. In this article we discuss the differential diagnosis of these complex processes. We also discuss in greater detail some of the most important interstitial lung diseases in the daily clinical practice.

UNITERMS: Lung Diseases, Interstitial.

\section{REFERÊNCIA BIBLIOGRÁFICA}

1 - JAMES DG. Sarcoidosis: past, present and future concepts. Clin Dermatol 4: 1-9, 1986.

\section{BIBLIOGRAFIA RECOMENDADA}

1 - COLBYTV et al. Atlas of pulmonary surgical pathology. W.B. Saunders, Philadelphia, 380 p, 1991.

2 - KALTREIDER HB. Hypersensitivity pneumonitis. West Med J 159: 570-578, 1993.
3 - SCHWARZ MI \& KING JR. TE. Interstitial lung disease. 2 th ed. Mosby Year Book, St. Louis, 508 p, 1993.

4 - THURLBECK WM \& CHURG AM. Pathology of the lung. 2 th ed. Thieme Medical Publishers, New York, 1178 p, 1995.

5 - WEBB WR; MÜLLER NL \& NAIDICH DP. High-resolution CT of the lung. 2 th ed. Lippincott Raven, Philadelphia, 320 , 1996.

Recebido para publicação em 13/05/98

Aprovado para publicação em 10/06/98 